\title{
Number agreement and event pluralization: A case study
}

Valentina Bianchi - June 2005

\section{Introduction}

In the recent minimalist framework, the number feature is taken to be interpretable when it is specified on a nominal category, but not when it is specified on a verbal category. This is actually a twofold assumption. On the one hand, the number feature on a verbal category is unvalued, and it must get a value by means of an Agree relation with a nominal category endowed with an interpretable (valued) number feature. On the other hand, even after it has got a value, the verbal number feature remains semantically irrelevant, i.e. it is not visible at the interface with the socalled Conceptual-Intentional system(s).

In this paper I wish to suggest that verbal number agreement is semantically relevant at least in a well-defined set of cases, and that its semantic import is event pluralization. The evidence that I will be discussing involves the Italian reciprocal modifier uno dopo l'altro (lit. 'one after the other'), exemplified in (1):

\section{(1) I soldati spararono uno dopo l'altro.}

the soldiers shoot-PAST.3.PL. one after the other

'The soldiers shot one after another.'

This modifier contains a form of the reciprocal expression (l) 'uno...l'altro, ${ }^{1}$ and it is interpretively related to an antecedent (the subject in (1)), with which it agrees in gender. Roughly speaking, the modifier expresses a temporal serialization of a set of events: in (1), there is a series of shooting events, each one having a different soldier as its Agent. This multiplicity of events will play a crucial role in my proposal. As a first step, I will point out three generalizations on the distribution of the reciprocal modifier.

\footnotetext{
${ }^{*}$ I wish to thank the audience at the XXXI IGG conference (Rome, February 2005), and in particular Adriana Belletti, Alex Grosu, Luigi Rizzi, Halldór SigurDsson, and Roberto Zamparelli for insightful comments. I am fully responsible for any remaining errors or inaccuracies.

${ }^{1}$ See Belletti (1982) for general discussion.
} 


\section{Three generalizations}

2.1. Current approaches to reciprocal expressions require a semantically plural antecedent for them, due to the inherent distributivity of the reciprocal interpretation (see, among many others, Heim, Lasnik and May 1991; Sternefeld 1998; Beck 2001). However, it can be shown that the reciprocal modifier requires an antecedent that is not only semantically, but also syntactically plural. The relevant evidence comes from certain quantifiers featuring a mismatch between syntactic and semantic number.

A clear example is the quantifier più di un NP 'more than one NP', which is semantically plural but syntactically singular (Partee 1995): it cannot antecede the reciprocal modifier, in sharp contrast with the syntactically and semantically plural quantifier almeno due NP 'at least two NPs':

(2) a. * Più di un soldato sparò uno dopo l'altro. more than one soldier shoot-PAST.3SG. one after the other

b. Almeno due soldati spararono uno dopo l'altro.

at least two soldiers shoot-PAST.3PL. one after the other

'At least two soldiers shot one after the other.'

Another example is the quantifier la maggior parte dei NP ('most NP', lit. 'the major part of the NPs'), which for some speakers can trigger either singular or plural verb agreement. For these speakers, the reciprocal modifier is incompatible with singular agreement, compare (3a) to (3b): ${ }^{2}$

(3) a. La maggior parte dei soldati hanno sparato uno dopo l'altro. the major part of the soldiers have-3.PL. shot one after the other 'Most soldiers shot one after another.'

b. * La maggior parte dei soldati ha sparato uno dopo l'altro. the major part of the soldiers has-3.SG. shot one after the other

\footnotetext{
${ }^{2}$ A possible assumption is that when syntactically singular, the quantifier actually introduces a group denotation, similar to collective NPs like the platoon. If we analyse a group as a special atomic individual (related to a plurality of ordinary individuals: see a.o. Landman 1989; Chierchia 1998), then the subject DP in (3b) would be also semantically non-plural. However, note that the quantifier triggering singular agreement does not necessarily take on a collective interpretation, e.g.:

(i) La maggior parte degli studenti ha risolto l'esercizio a casa propria. the major part of the students has-SG. solved the exercise at home self 'Most students correctly solved the exercise at home.'
} 
A third example is the quantifier phrase qualche NP 'some NP-SG.', discussed by Zamparelli (2004): though syntactically singular, it is semantically compatible either with a singular or with a plural interpretation - depending on the context - and allows for plural intersentential anaphora. However, its potential semantic plurality is not sufficient to license the reciprocal modifier, as shown in (4).

* Qualche soldato ha sparato uno dopo l'altro. some soldier has-3.SG. shot one after the other

Finally, the relative pronoun chi 'who' in free relatives can receive a quasiuniversal interpretation, and it supports a reciprocal interpretation for the $s i$ clitic in (5a); however, it is syntactically singular, and it cannot antecede the reciprocal modifier in $(5 b):^{3}$

\section{(5) a. Chi si ama si perdona.}

who si love-3.SG. si forgive-3.SG.

'Those who love each other forgive each other.'

b. * Chi arriva uno dopo l'altro si mette in fila. who arrive-3.SG. one after the other stand-3.SG. in a row

These data suggest that syntactic plurality of the antecedent is a necessary condition to license the reciprocal modifier. ${ }^{4}$

2.2. A second constraint on the reciprocal modifier concerns the possible grammatical role of the antecedent. In all of the above

\footnotetext{
${ }^{3}$ Thanks to Alex Grosu (p.c.) for pointing out these data.

${ }^{4}$ Syntactic plurality is not a sufficient condition without semantic plurality: a syntactically plural argument cannot license the reciprocal modifier when the predicate requires a group interpretation for it:

(i) * I soldati si incontrarono nel cortile uno dopo l'altro. the soldiers met-PAST.3.PL. in the yard one after the other

Collective noun phrases also cannot antecede the reciprocal modifier in Italian; I take them to be both semantically and syntactically singular (cf. note 3). Pollard and Sag (1994: 70-71) show that in certain varieties of English collectives can trigger plural agreement; the plural vs. singular agreement correspond to an aggregate vs. nonaggregate (atomic) mode of individuation of the referent. $\mathrm{H}$. SigurDsson (p.c.) informs me that in Icelandic the reciprocal modifier hver á fcetur öDrum, lit. "each on feet other's' allows for a collective antecedent triggering singular agreement on the predicate (e.g. the collective noun fólk).
} 
examples, the antecedent is the subject of the sentence. The antecedent can also be a direct object, as shown in (6):

(6) Maria ha ingoiato tre panini uno dopo l'altro.

Maria has swallowed three sandwiches one after the other

'Maria swallowed three sandwiches one after another.'

But the antecedent cannot an indirect object or another prepositional object:

(7) a. ?* Ho telefonato ai miei colleghi uno dopo l'altro.

(I) have-1.SG. phoned to my colleagues one after the other

b. ?* Ho parlato con gli studenti uno dopo l'altro.

(I) have spoken with the students one after the other

This constraint cannot be derived from the anaphoric nature of the reciprocal expressions, for anaphors in general can be bound by prepositional complements (see Belletti 1982: 117-118 on this point). Belletti (1982) reduces this constraint to her movement analysis, whereby the first part of the reciprocal expression (l'uno) moves and adjoins to the antecedent in LF: if the antecedent is embedded in a PP, the moved part does not c-command the empty category left by movement, violating the Proper Binding Condition. (In current terms, raised $\left(l^{\prime}\right)$ uno could not countercyclically adjoin to a DP that is embedded in a PP. $)^{5}$

(8) ho telefonato [pP a [DP (l')uno [i miei colleghi]] [1'une [dopo l'altro]]

One problem with this idea is that it does not extend to English, where the reciprocal each other can be anteceded by a prepositional complement, although each-movement is standardly assumed. ${ }^{6}$ Anyway, the problem with c-command does not even arise in (7) if one adopts Kayne's (2003)

\footnotetext{
${ }^{5}$ The same problem would arise in a doubling derivation (Belletti 2003, Kayne 2002), whereby the antecedent would move away, stranding the reciprocal:

(i) telefonato [PP a [DP i miei colleghi]] [(1')uno [i miei colleghi] [dopo l'altro]]

${ }^{6}$ (i) I talked to John and Bill about each other.

(ii) I heard from John and Bill about each other. (from Jackendoff 1990, (14))

Belletti (1982: n. 22) argues that English each other is not subject to LF extraction of each, contrary to Heim, Lasnik \& May (1991), among others.
} 
approach to prepositions as probes, attracting their purported complement to a specifier position c-commanding the base VP-internal position.

I wish to suggest an alternative view of (7), capitalizing on the observation that in Italian, indirect (and generally prepositional) objects can never trigger number agreement on the verb.

Note that subjects regularly trigger finite verb agreement, which involves a verbal functional projection ( $\mathrm{T}$ or $\mathrm{Agr}-\mathrm{S}$ ). As for direct objects, in contemporary Standard Italian they only trigger a residual form of past participle agreement when they are realised as clitics; ${ }^{8}$ however, under standard assumptions direct objects too establish an Agree relation with a low verbal head endowed with phi-features (little v or Agr-O), in order to license/value their structural Accusative Case feature. On the contrary, indirect and prepositional objects can never trigger participle agreement strikingly, not even when they are morphologically identical to the Accusative clitics, as in the first and second person (compare (9) to (10)):

(9) Ci hanno invitate.

1.PL have-3-PL. invited-F.PL.

'They invited us' (female speaker and addressee(s))

(10) * Ci hanno parlate.

1.PL have-3-PL. spoken-F.PL.

'They spoke to us' (female speaker and addressee(s))

Even if the indirect object is assumed to bear a structural Dative Case (see Kayne 2003), it is far from clear that this Case licensing involves agreement for phi-features; on the contrary, it appears that the presence of the preposition somehow blocks agreement (see Belletti and Rizzi 1995 for discussion). ${ }^{9}$ I wish to propose that this is the crucial property that accounts for (7): indirect/prepositional objects, contrary to subjects and direct objects, do not establish a number agreement relation with any functional head associated to the verb.

There is also some further evidence for the relevance of number agreement in licensing the reciprocal modifier. As discussed by Cinque (1988: 554-

\footnotetext{
${ }^{7}$ With subsequent remnant VP movement to a higher Specifier.

${ }^{8}$ On participial agreement see Kayne (1989, 1993); Friedeman \& Siloni (1997); on Italian, see especially Egerland (1996).

${ }^{9}$ Or possibly Dative Case does, even when it is not (overtly) prepositional: cf. the impossibility for Dative quirky subjects to control verbal number agreement in Icelandic (see SigurDsson 2000, Taraldsen 1995, among others).
} 
558), in transitive clauses involving the impersonal clitic si the verb usually agrees in number with the thematic object (11a), but it may sometimes fail to agree with it, as an (idiolectally restricted) option (11b):

(11) a. Da qui si vedono le montagne.

from here si see-3.PL. the mountains

b. \% Da qui si vede le montagne.

from here si see-3.SG. the mountains

'One can see the mountains from here.'

Although the judgements are delicate, a correlation seems to emerge: when the reciprocal modifier is anteceded by the impersonal subject, the nonagreeing version is preferred (for those speakers who accept this option).

(12) a. ?* Per fare l'effetto-onda, si alzano le mani uno dopo l'altro. to make the wave-effect, si raise-3.PL. the hands one after the other b. ? Per fare l'effetto-onda, si alza le mani uno dopo l'altro. to make the wave-effect, si raise-3.SG. the hands one after the other 'To make the wave-effect, people raise their hands one after another.'

In (12a), number agreement with the thematic object seems prevent the impersonal subject from anteceding the reciprocal modifier. ${ }^{10}$

An obvious objection is that even in (12b), the impersonal subject does not seem to trigger plural number agreement on the finite verb, which appears in a default (third person singular) form. Note however that the impersonal subject does trigger plural agreement on participial and adjectival predicates, as shown in (13):

\footnotetext{
${ }^{10}$ When the antecedent is the thematic object, the agreeing version is preferable; but since this is the least marked option, this contrast is not really informative:

(i) In questo esercizio di ginnastica, si alzano/ ?? alza le mani una dopo l'altra. In this gym exercise, si raise-3.PL/?? 3.SG the hands one after the other 'In this gym exercise, you have to raise your hands one after the other.' Cinque (1988: 554-558) argues that the agreeing option in (12a) involves a [+argument] clitic $s i$, whereas the non-agreeing option involves [-argument] $s i$ and an argumental pro subject; the former is incompatible with reciprocal l'uno...l'altro because there is no [+plural] NP antecedent to which l'uno could possibly adjoin (Cinque 1988: 540-541; cf. (8) above). In the account to be proposed here, the [+plural] NP is required for different reasons (see below $\S 3$ ).
} 
(13) Si viene criticati.

si get-3.SG. criticized-M.PL.

'One gets criticised.'

I will return below to this interesting split in number agreement.

On the basis of these data, I wish to propose the following hypothesis: in order to license the reciprocal modifier uno dopo l'altro, the antecedent must trigger number agreement on the modified predicate.

2.3. A third constraint on the distribution of the reciprocal modifier concerns the nature of the modified predicate. In all of the above examples, the predicate is stage-level. The reciprocal modifier is impossible if the modified predicate is individual-level (14), or more generally stative (15):

(14)?* I miei antenati sono stati alti e biondi uno dopo l'altro. my ancestors are-3.PL. been-M.PL. tall and blonde one after the other

(15) a. ?* I soldati restarono immobili uno dopo l'altro. the soldiers remained-3.PL. still one after the other

b. * I soldati erano spaventati uno dopo l'altro. the soldiers were-IPF. 3.PL. afraid one after the other

There is an even stricter Aktionsart constraint: durative atelic predicates, as in (16) are much less felicitous that a telic predicate like 'shoot':

(16)a. ? I soldati camminarono uno dopo l'altro. the soldiers walked-3.PL. one after the other

b. ? I ragazzi dormirono uno dopo l'altro. the boys slept-3.PL. one after the other

c. * I ragazzi russarono uno dopo l'altro. the boys snored-3.PL. one after the other

(16a-b) are marginally acceptable only if the atelic predicates receive an inchoative interpretation (denoting the inception of the event) or if they denote contextually bounded events (e.g. a walk along a well defined path, or a fixed sleeping interval); no such interpretation is available in the case of (16c). This suggest the requirement for an inherently bounded event.

Bach (1986) proposed an interesting parallel between the mass-count distinction in the nominal domain and the event-process distinction in the "aspectual" (Aktionsart) domain. Under his view, telic predicates denote atomic eventualities (events), with the property of indivisivity (no proper 
part of a telic event can be a telic event falling under the same predicate). Atomic events can be i-joined (à la Link 1983) to form plural events; they allow for count modifiers (17a), but not for mass modifiers (17b):

\section{(17) a. John fell asleep three times last night.}

b. (*) John found a unicorn a lot last night.

On the contrary, stative - and generally, atelic - predicates denote "mass", non-atomic eventualities, with the property of divisivity (a proper part of an atelic eventuality can be an atelic eventuality falling under the same predicate; e.g. a proper part of a walk can be a walk). Atelic eventualities cannot be i-joined to form a plural eventuality; they do not allow for count modifiers, as in (18a), but only for mass modifiers, as in (18b):

(18) a. (*) John slept three times last night.

b. John slept a lot last night.

Capitalizing on Bach's parallelism, we can draw the following conclusion: the reciprocal modifier uno dopo l'altro can only be licensed in a clause that contains an event variable ranging over atomic (countable) events.

2.4. To summarize the preceding discussion, I have proposed the following three generalizations on the distribution of the reciprocal modifier:

(i) there must be a syntactically and semantically plural antecedent in the clause;

(ii) the modified predicate must agree in number with the antecedent;

(iii) the modified predicate must denote atomic events.

The idea that I will explore is that via syntactic number agreement, the plural feature of the antecedent can be transmitted to the predicate, so that the latter comes to denote a plural event, i.e. a sum of individual events that can be distributed over and be temporally ordered one after the other.

\section{Verbal plurality}

Starting from Link's (1983) seminal work, pluralization has been conceived of as an operation applying to the denotation of a count noun (a set of individuals) to yield a structured domain constituted by all the possible 
sums of these individuals into pluralities. ${ }^{11}$ Recently, Heycock and Zamparelli (2004) have proposed a syntactic implementation of the pluralization operation as a functional head (dubbed Pl) selecting the NP projection, and taking the denotation of the latter as its argument:

(19) $\mathbb{[}[\mathrm{NP}$ soldato $] \rrbracket=\{\{\mathrm{al}\},\{$ ben $\},\{$ carl $\}\}$

(20) $\llbracket[$ [PIP soldati $] \rrbracket=\llbracket P 1 \rrbracket(\llbracket[$ NP soldato $] \rrbracket)=\{\{a\},\{b\},\{c\},\{a, b\}$, $\{a, c\},\{b, c\},\{a, b, c\}\}$

I propose that a parallel $\mathrm{Pl}$ head selects the verb phrase:

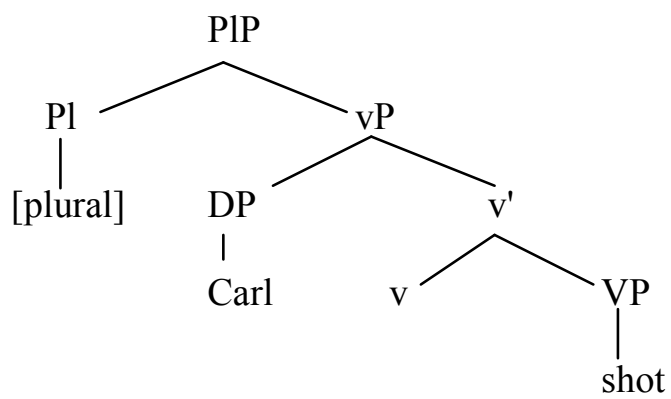

Under current assumptions, the $\mathrm{vP}$ denotes (the characteristic function of) a set of shooting events whose Agent is Carl (see e.g. Kratzer 1996). If the Pl head has a [plural] feature, the PIP will denote a set of plural shooting events whose Agent is Carl (e.g. in Carl shot three times).

Consider however our initial example, repeated here as (22):

(22) I soldati spararono uno dopo l'altro.

the soldiers shoot-PAST.3.PL. one after the other

'The soldiers shot one after another.'

Here we do not want to obtain a set of plural events each of which has all the soldiers (i.e. the whole DP denotation) as the Agent, but rather, a plurality of events each of which has an individual part of the denotation of [[DP the soldiers] $]$ as its Agent.

\footnotetext{
11 The resulting structure is a complete join semilattice minus the bottom element. The relevant literature is too vaste to be summarized here; see Landman (1996).
} 
This can be obtained by pluralizing a relation between individuals and events via the double star ** operator (Sternefeld 1998; Beck 2001):

(23) ** is that function such that for any two place relation $\mathrm{R}, \mathrm{x}, \mathrm{y}:[* * \mathrm{R}](\mathrm{y})(\mathrm{x})$ iff (i) $\mathrm{R}(\mathrm{y})(\mathrm{x})$, or (ii) $\exists \mathrm{x}_{1} \mathrm{x}_{2} \mathrm{y}_{1} \mathrm{y}_{2}\left[\mathrm{x}=\left(\mathrm{x}_{1} \oplus \mathrm{x}_{2}\right) \& \mathrm{y}=\left(\mathrm{y}_{1} \oplus \mathrm{y}_{2}\right) \& * * \mathrm{R}\left(\mathrm{y}_{1}\right)\left(\mathrm{x}_{1}\right) \& * * \mathrm{R}\left(\mathrm{y}_{2}\right)\left(\mathrm{x}_{2}\right)\right]$ (where $\mathrm{x}_{1} \oplus \mathrm{x}_{2}$ is the smallest $\mathrm{x}$ such that $\mathrm{x}_{1} \leq \mathrm{x} \& \mathrm{x}_{2} \leq \mathrm{x}$ )

Suppose that we take the vP in (22) to denote a two-place relation between individuals and events, rather than a set of events:

(24) $\lambda x . \lambda e .(\operatorname{shoot}(x, e))$

(24) is a relation holding between an individual $\mathrm{x}$ and an event $\mathrm{e}$ if and only if $\mathrm{x}$ is the Agent of $\mathrm{e}$ and $\mathrm{e}$ is a shooting event. Suppose now that the Pl head above $\mathrm{vP}$ encodes the ${ }^{* *}$ operator, applying to this two-place relation between individuals and events. The double-starred relation will hold between an overall plural shooting event $\mathrm{E}$ and the soldiers set denoted by the subject DP if and only if for every individual part of the soldiers set there is an atomic shooting event of which he is the Agent, and vice versa:

(25) $<$ E, $\mathbb{[}[$ DP the soldiers $] \rrbracket>\in * * \lambda x . \lambda$ e. $(\operatorname{shoot}(\mathrm{x}, \mathrm{e})) \leftrightarrow$

(26) $\left(\forall \mathrm{x} \leq_{\mathrm{i}}[\right.$ [DP the soldiers] $\rrbracket)\left(\exists \mathrm{e} \leq_{\mathrm{i}} \mathrm{E}\right)(\operatorname{shoot}(\mathrm{x}, \mathrm{e})) \&\left(\forall \mathrm{e} \leq_{\mathrm{i}} \mathrm{E}\right)\left(\exists \mathrm{x} \leq_{\mathrm{i}} \mathbb{[}[\mathrm{DP}\right.$ the soldiers] ]) (shoot $(\mathrm{x}, \mathrm{e}))$ (where $\leq_{\mathrm{i}}$ is the individual part relation) ${ }^{12}$

In order to obtain the two-place vP denotation (24), I propose that a Pl head encoding the ** operator attracts a [+plural] DP argument to its Spec, in order to check/value its own [+plural] feature. This leaves in the vP an individual variable that can be abstracted over to yield the required twoplace relation:

\footnotetext{
${ }^{12}$ Beck (2001) argues that the ** operator is sensitive to a contextually relevant cover, i.e. a partition of the plural denotations to be distributed over. A plural reciprocal expression in the modifier is felicitous only if the context provides a way to partition the set of the soldiers in at least two subgroups:

(i) I soldati spararono gli uni dopo gli altri.

the soldiers shot-PAST.3.PL. the ones after the others

The singular reciprocal in (22) instead requires a partition into individual parts. The role in determining a cover for the DP is evident in the case of the cognate modifiers uno a uno 'one by one', due alla volta 'two at a time', etc.
} 


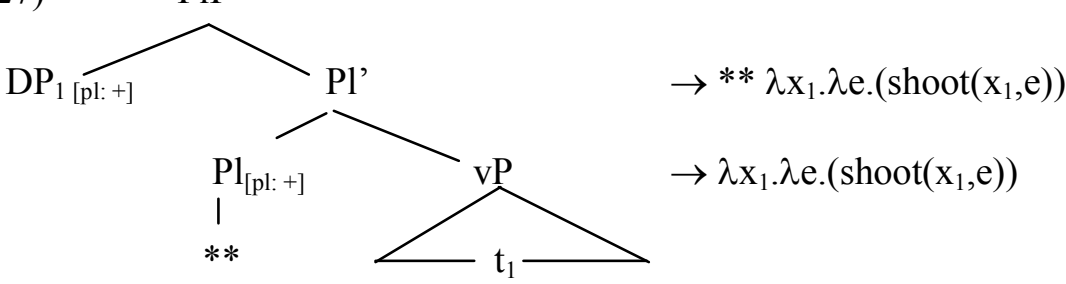

Syntactic number agreement in the PIP layer pluralizes the individual-event relation: hence, it must be visible at the interface with the C-I system(s).

A full compositional analysis of the reciprocal modifier uno dopo l'altro would exceed the limits of the present discussion. An obvious problem is the fact that the syntactic antecedent of the reciprocal is a DP, but semantically, the modifier does not temporally order the individuals in the DP denotation (rather, the atomic subevents that these individuals are involved in). ${ }^{13}$ I will not try to develop a semantic analysis; on the syntactic side, I will simply assume that the reciprocal modifier is hosted in a functional projection immediately above the [+plural] PIP layer.

Having proposed a syntactic implementation of verbal plurality, I can now go back to the three generalizations discussed in $\S 2$.

First, there must be a syntactically (as well as semantically) [+plural] argument inside the vP, because only such an argument can check/value the [+plural] feature on the verbal Pl head.

Second, the [+plural] argument must be able to establish a number agreement relation with the verbal functional head $\mathrm{Pl}$, in order to license the [+plural] feature of the latter, in the way described in (27). This is possible for a DP argument (a subject or a direct object); on the contrary, a prepositional argument cannot establish such an agreement relation, for reasons that remain to be understood.

Third, the modified predicate must be eventive and telic because only such a predicate has a Davidsonian event position ranging over atomic events, which allow for pluralization (giving rise to sums of atomic events). ${ }^{14}$

\footnotetext{
${ }^{13}$ Possibly, the temporal preposition dopo take as a complement an elliptical clause rather than a simple DP. I will not try to explore this possibility here.

${ }^{14}$ It is beyond the scope of this paper to explore to what extent the generalizations hold of other instances of the reciprocal expression in Italian. L'uno...l'altro seems to obey the first two generalizations in all of its instances; it is possible to speculate that all these reciprocal structures involve pluralization of a Davidsonian e-position (whereby each pair of individuals in a reciprocal relation would correspond to a distinct subevent or subsituation). See Beck (2001) for an application of the eposition to certain reciprocal interpretations.
} 


\section{The syntactic position of the reciprocal modifier}

In (21) and (27), I have proposed a very low position for the Pl projection in the immediate periphery of the verb phrase - essentially for reasons of semantic compositionality: just as in the case of the noun phrase (see (19)), here too the Pl head applies to the lexical layer in order to yield a plural denotation. Zamparelli (2000) and Heycock and Zamparelli (2004) argue that semantic compositionality is a valid criterion to establish the relative order of functional layers, a view that I fully endorse.

The criterion of semantic compositionality can also be used to establish the position of the proposed PIP layer with respect to some higher layers. Consider for instance the following examples:

(28) a. Quando entrava il preside, gli studenti si alzavano uno dopo l'altro. when came-in-IPF.3.SG. the dean, the students si stood-IPF.3.PL. one. after the other

'When the dean came in, the students used to stand up one after another.'

b. Maria stava divorando i miei panini uno dopo l'altro.

Maria was-IPF.3.SG swallowing my sandwiches one after the other

'Maria was swallowing my sandwiches one after another.'

(28a) is a habitual sentence, expressing a quasi-universal quantification over events (cf. among others Bonomi 1997). Note that this quasi-universal quantification affects the overall plural event in which all the students stand up one after the other: this means that the plural event is available for aspect to operate on. Similarly, in (28b) it is the overall plural event that is seen in its progress: for the sentence to be true, there must be a non-null sequence of individual events (each involving a single sandwich) preceding the focalization point of the progressive aspect. These considerations suggest that the Pl projection and the reciprocal modifier are placed below the aspectual projection Asp(generic/progressive) proposed by Cinque (1999): this confirms the low syntactic position proposed above.

Besides these compositionality arguments, it is also useful to take a closer look at the syntactic positions in which the reciprocal modifier can appear. ${ }^{15}$ I am making the crucial assumption that the reciprocal modifier

15 One structure that I will not discuss is the apparently DP-internal reciprocal modifier exemplified in (i): 
uno dopo l'altro sits in a functional layer immediately adjacent to PIP; under this assumption, the syntactic evidence that I am going to discuss will also indirectly bear on the syntactic position of PIP.

The unmarked position of the modifier follows all the verb complements and the lowest adverbs of Cinque's (1999) hierarchy. However, this rightmost linear position would be compatible with a relatively high structural position if we assume that the reciprocal modifier can be rightadjoined. If we exclude this possibility, it is still possible that the modifier sit in a left-hand specifier and be crossed over by remnant VP movement (à la Kayne 2003). Thus, the rightmost position is not really informative w.r.t. the hierarchical placement of the modifier.

More interestingly, in compound tenses the reciprocal modifier can also appear in an intermediate clausal position. Here we find a striking contrast: a reciprocal modifier anteceded by a transitive subject can marginally appear in between the auxiliary and the participle (29a); this position is instead unavailable for a modifier anteceded by the direct object (29b):

(29) a. ? Gli studenti hanno [uno dopo l'altro] eseguito il brano musicale. the students have-3.PL. one after the other played the piece of music 'The students played the piece of music one after another.'

b. * Mio cugino ha [uno dopo l'altro] eseguito tutti i brani musicali. my cousin has-3.SG. one after the other played all the pieces of music

We can account for this contrast in terms of head-to-head movement of the participle (cf. Cinque 1999). Suppose that there is a higher position for the subject-related modifier and a lower position for the object-related one: the past participle necessarily moves beyond the lower layer (as indicated by the solid arrow), whereas movement across the higher layer is optional (as indicated by the dotted arrow):

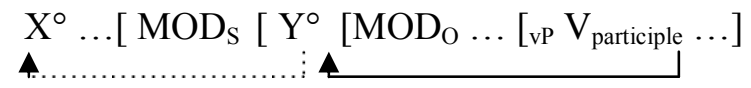

There is some more evidence in support of two functional layers hosting the reciprocal modifier. The modifier can appear in a clause-initial position:

(i) Leggeva un libro dopo l'altro.

read-IPF.3.SG. one book after the other

'(s)he read one book after another.' 
(31) a. Uno dopo l'altro, i soldati abbassarono il fucile.

one after the other, the soldiers laid-down-PAST.3.PL. the gun

'The soldiers laid down their guns one after another.'

b. ? Uno dopo l'altro, ha ingoiato tutti i panini.

one after the other, has-3.SG. swallowed all the sandwiches

'(S)he swallowed all the sandwiches one after another.'

I assume that this position is derived by some sort of adverbial fronting. Interestingly, it is also possible to have two co-occurring reciprocal modifiers, one in the clause-initial position and another one in the clausefinal position, each having a distinct antecedent:

(32) Uno dopo l'altro, i ragazzi alzano le due bandiere una dopo l'altra. o.-M. after oth.-M., the boys lift the two flags-F. o-F. after oth.-F.

'One by one, the boys lift each his two flags one after the other.'

The possibility of two reciprocal modifiers suggests a recursion of the relevant functional layer, but this is not an unordered recursion. In fact, there is a sharp contrast between (32), where the fronted modifier is anteceded by the subject and the clause-final one by the direct object, and (33), where the modifier anteceded by the direct object is fronted across the one anteceded by the subject:

(33) * Una dopo l'altra, i ragazzi alzano le due bandiere uno dopo l'altro. o.-F. after oth.-F., the boys lift the two flags-F. o.-M. after oth.-M.

This looks like a Relativized Minimality effect. Assume, as above, that the subject-related modifier is inserted in a higher layer than the object-related one. If the subject-related modifier is fronted, no intervention effects arise:

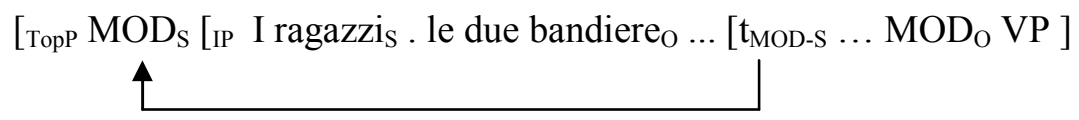

On the contrary, if the lower object-related modifier is fronted, it moves across the higher subject-related one, which creates an intervention effect:

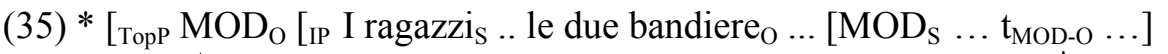


The evidence in (29)-(35) suggests two hypotheses: first, there can be recursion of the layer hosting the reciprocal modifier (and of the related PIP layer); second, this recursion is intrinsically ordered: the higher layer is reserved for the subject-related modifier (and event pluralization triggered by a plural subject), whereas the lower layer is reserved for the objectrelated modifier (and event pluralization triggered by a plural direct object). Although the distinction between a subject-related and an object-related functional layer is reminiscent of the Agr-S vs. Agr-O architecture, I am actually claiming that both these layers are quite low in the functional structure of the clause, in the periphery of the verb phrase. One way to implement the distinction would be to assume that the higher reciprocal modifier and the corresponding PIP projection are placed above $\mathrm{vP}-$ the layer which introduces the transitive subject - whereas the lower reciprocal modifier and PIP are placed below little $\mathrm{V}$ and above VP, at a structural level which only c-commands the merge position of the direct object, but not that of the subject. Unfortunately, it is quite difficult to find empirical evidence in support of this specific functional structure.

\section{Back to interpretability: "high" vs. "low" number}

The evidence discussed in $\S 4$ supports the following conclusions: there are two distinct functional layers responsible for event pluralization in the periphery of the verb phrase and - whatever their exact position in the functional sequence - the higher one is reserved for the transitive subject, the lower one for the direct object.

These conclusions imply an apparently redundant duplication of the number feature in the clausal functional structure: this would be checked/valued by the subject in the vP-peripheral $\mathrm{Pl}$ projection, but also in the phi-feature bundle of the functional head that is responsible for Nominative Case licensing (Tense or Agr-S), which is quite high in the functional structure. Why should Universal Grammar allow for such a double checking of the number feature?

From a minimalist perspective, a possible anwer is that $\mathrm{vP}$ and $\mathrm{CP}$ are distinct phases, and the subject is the distinguished argument that is involved in the computation of both, since it originates within the vP phase but it must be Case-licensed in the higher CP phase. This is, at best, a theory-internal answer. However, there is also some independent empirical evidence that supports this double representation of number.

As is well known from the literature, there are some interesting structures featuring a number agreement mismatch, whereby number agreement on 
the finite verb form and non-finite (participial/adjectival) number agreement differ, even though syntactically one and the same argument is involved (see, among others, Cinque 1988; Kayne 1989; Wechsler 2002). One relevant example is the impersonal si construction in Italian, exemplified in (13) above and in (37): here the finite verb is in the singular, whereas all non-finite predicates appear in the plural.

\section{(37) Si è stati criticati.}

si be-3.SG. been-M.PL. criticized-M.PL.

'One got criticised.'

The reverse pattern emerges with the well known politeness plural second person, which is commonly used in French and in earlier stages of Italian to formally address a single interlocutor. Here the finite verb appears in the plural second person, but all non-finite predicates appear in the singular. ${ }^{16}$

\section{(38) Siete stato dichiarato colpevole. \\ are-2.PL. been-M.SG. declared-M.SG. guilty-SG. \\ 'You were found guilty.'}

These mismatches could be reduced to an opposition between grammatical and semantic agreement, roughly in the sense of Wechsler (2002) (see also Pollard and Sag 1994: 60-99). Simplifying considerably, under this view certain instances of morphological agreement are driven by a purely grammatical number features, whereas others are triggered by a semantic number feature, corresponding to the intrinsic (or pragmatically relevant) properties of the referent, that is, its individuation as an aggregate or nonaggregate entity. In (37), we could assume that the impersonal subject lacks a grammatical [plural] feature, but it is semantically plural; the finite verb undergoes grammatical agreement, whereas the participles and the nominal predicate undergo semantic agreement. Conversely, in (38) the politeness second person subject may be formally [plural], but semantically singular in that it refers to a single addressee; the finite verb undergoes grammatical agreement, and the non-finite predicates semantic agreement. It is fair to say that these agreement mismatches can hardly be expressed by the syntactic mechanism of Agree. The interface question of the relationship between syntactic and semantic number is extremely complex; ${ }^{17}$

\footnotetext{
${ }^{16}$ Agreement with politeness forms is actually subject to cross-linguistic variation (see e.g. Comrie 1975).The topic is too vaste to be fully addressed here.

${ }^{17}$ See Heycock \& Zamparelli (2004) on plurality in the noun phrase.
} 
nevertheless, I believe that the data in (37) and (38) show a regularity that we can try to make sense of.

The crucial observation is that the distribution of formal vs. semantic number agreement is not random, but it correlates with the property of finiteness. Both in (37) and in (38), finite agreement is formal/syntactic, whereas non-finite agreement is semantic. The next question is, then, what distinguishes finite from non-finite agreement. In Bianchi (2003), it is argued that the crucial difference is the presence vs. absence of the [person] feature. Capitalizing on an insight by Wechsler (2002), we can speculate that finite number agreement is somehow parasitic on person agreement. ${ }^{18}$ In (37), the impersonal subject of the si construction plausibly bears a [+plural] feature and a defective person feature: the latter fails to trigger full person agreement, which would in turn entail the impossibility of parasitic number agreement, yielding a default inflection on the finite verb form (cf. Cinque 1988: 537). In (38), instead, the apparent plural number agreement can be though of as a consequence of person agreement with an "augmented" second person, i.e. as a form of honorific agreement. ${ }^{19}$

In both cases, the finite number agreement that is syntactically expressed in the higher part of the clausal functional structure is parasitic on person and, crucially, blind to semantic number. On the contrary, non-finite number agreement is insensitive to person, whereas it is sensitive to semantic number. We can now assume that non-finite number agreement is the morphological manifestation of the proposed Pl layers in the lower part of the clausal functional structure: the number feature that they express is semantically relevant at the interface with the C-I systems, hence they are sensitive to the semantic plurality of the agreement trigger.

This brings us back to the question that we started with, namely, the interpretability of the number feature in the clausal functional structure. As mentioned above, the number feature that expresses event pluralization must be relatively low, in particular, lower than the functional layers that quantify over (bind) the Davidsonian event variable. On the other hand, the

\footnotetext{
${ }^{18}$ This can be directly captured in an approach where both person and "high" number are realised on one and the same head (T or AgrS); but see SigurDsson (2004), among others, for a split projection of person and number.

${ }_{19}$ According to Wechsler (2002), second person plural agreement is actually pure person agreement. I cannot adopt Wechsler's radical hypothesis that the second person plural pronoun lacks a formal [+plural] feature in all of its instances, because a semantically plural second person pronoun can antecede the reciprocal modifier, which I have argued requires a syntactically as well as semantically plural antecedent.
} 
"high" number feature is projected above the aspectual/Tense layers that bind the event variable, and it could not possibly yield event pluralization; thus, it cannot be semantically interpretable in the same way as "low" number is. The different status of the number feature in the two cases is entirely expected from the viewpoint of semantic compositionality.

\section{Concluding remarks.}

In this paper I have provided some evidence that verbal number agreement can be semantically relevant and yield event pluralization. The evidence only consists in one specific case study; it is impossible here to draw any more general conclusion, beyond the obvious implication that such possibility is at least allowed by Universal Grammar.

Despite its admittedly limited empirical scope, this proposal has some interesting implications on the methodological side. Starting from Abney's (1987) seminal work, it is customary to draw a parallelism between the functional structure of the noun phrase and that of the clause. This usually consists in importing in the noun phrase such clausal categories as Complementizer, Inflection etc. (see Giusti (2005) for recent discussion). In my analysis I have proposed an assimilation in the opposite direction: that is, I have imported a functional head of the noun phrase structure $(\mathrm{Pl})$ in the clause. From this perspective, the functional structure above NP and vP is even more strictly parallel than it is usually thought. I believe that this is entirely reasonable in the light of the parallelism in the structure of the nominal and verbal denotation domains pursued by Bach (1986), Krifka (1992), and others.

Secondly, the proposed analysis shows a welcome convergence between syntactic arguments and semantic compositionality arguments in individuating the functional architecture of a phase. To the extent that it is correct, my proposal further corroborates Heycock and Zamparelli's approach. I believe that both these issues - the parallelism of nominal and clausal projections, and the issue of the semantic compositionality of functional layers - deserve a thorough investigation in the cartographic approaches to phase structure. 


\section{References}

Abney, Steven

1987 The English noun phrase in its sentential aspects. Ph.D. diss., MIT.

Bach, Emmon

1986 The algebra of events. Linguistics and Philosophy 9:5-16.

Beck, Sigrid

2001 Reciprocals are definites. Natural Language Semantics 9: 69-138.

Belletti, Adriana

1982 On the anaphoric status of the reciprocal construction in Italian. The

Linguistic Review 2:101-137.

Belletti, Adriana

2003 Extended doubling and the VP periphery. Ms., University of Siena.

Belletti, Adriana, and Luigi Rizzi

1995 Su alcuni casi di accordo del participio passato in francese e in italiano, Ms., University of Siena.

Bianchi, Valentina

2003 On finiteness as logophoric anchoring. In: Temps et point de vue / Tense and Point of View, Jacqueline Guéron and Liliane Tasmovski (eds.), 213-

246. Paris: Université Paris X - Nanterre.

Bonomi, Andrea

1997 Aspect, quantification, and when-clauses in Italian. Linguistics and Philosophy 20:469-514.

Chierchia, Gennaro

1998 Plurality of mass nouns and the notion of "semantic parameter". In

Events and Grammar, S. Rothstein (ed.), 53-104. Dordrecht: Kluwer.

Cinque, Guglielmo

581

1988 On si constructions and the theory of $a r b$. Linguistic Inquiry 19: 521-

Cinque, Gugliemo

1999 Adverbs and Functional Heads, New York: Oxford University Press

Comrie, Bernard

1975. Polite plurals and predicate agreement. Language 51: 406-418.

Egerland, Verner

1996 The Syntax of Past Participles. A Generative Study of Nonfinite Constructions in Ancient and Modern Italian. Lund: Lund University Press

Friedeman, Marc Ariel and Tal Siloni

1997 Agrobj is not Agrparticiple. The Linguistic Review 14: 69-96.

Giusti, Giuliana

2004 At the left periphery of the noun phrase. Paper presented at the XXXI IGG conference (Rome, 2005).

Heim, Irene, Howard Lasnik, and Robert May

1991 Reciprocity and plurality. Linguistic Inquiry 22: 63-101.

Heycock, Caroline And Roberto Zamparelli 
2004 Friends and colleagues: plurality, coordination, and the structure of DP. Ms., University of Edinburgh and University of Bergamo. To appear in Natural Language Semantics.

Jackendoff, Ray

1990 On Larson's treatment of the double object construction. Linguistic Inquiry 21: 427-

Kayne, Richard S.

1989 Facets of Romance past participle agreement, in Dialect Variation and the Theory of Grammar, Paola Benincà (ed)., 55-84. Dordrecht: Foris

Kayne, Richard S.

1993 Toward a modular theory of auxiliary selection, Studia Linguistica 47: 3-31.

Kayne, Richard S.

2002 Pronouns and their Antecedents. In Derivation and Explanation in the Minimalist Program, S.Epstein \& D.Seely (eds.). London: Blackwell.

Kayne, Richard S.

2003 Prepositions as probes. Forthcoming in Structures and Beyond. The Cartography of Syntactic Structures, vol. 3, A.Belletti (ed.), New York: Oxford University Press.

Kratzer, Angelika

1996 Severing the external argument from its verb. In: Phrase Structure and the lexicon, Johan Rooryck and Laurie Zaring (eds.), 109-137. Dordrecht: Kluwer.

Krifka, Manfred

1992 Thematic relations as links between nominal reference and temporal constitution. In Lexical Matters, Ivan Sag and Anna Szabolsci, (eds.), 29-53. Stanford: Stanford University Press,.

Landman, Fred

1989 Groups I. Linguistics and Philosophy 12: 559-605

Landman, Fred

1996 Plurality. In: The Handbook of Contemporary Semantic Theory, Lappin, Shalom (ed.), 425-457. London: Blackwell.

Link, Godehard

1983 The logical analysis of plural and mass terms: a lattice-theoretic approach. In: Meaning, Use and Interpretation of Language, Bauerle, Schwartze \& von Stechow, (eds.), 302-323. Berlin: Walter de Gruyter.

Partee, Barbara.

1995 Quantificational structures and compositionality. In Quantification in Natural Languages, Emmon Bach et. al. (eds.), 541-601. Dordrecht: Kluwer.

Sternefeld, Wolfgang

1998 Reciprocity and cumulative predication, Natural Language Semantics 6: 303-337.

Taraldsen, Knut T. 
1995 On agreement and Nominative objects in Icelandic, in: Studies in Comparative Germanic Syntax II, Hubert Haider, Susan Olsen and Sten Vikner (eds.), 307-327. Dordrecht: Kluwer

Pollard, Carl and Ivan Sag

1994 Head-driven Phrase Structure Grammar. Stanford: CSLI

Publications.

Wechsler, Steven

2002 Number as person, in: Empirical Issues in Syntax and Semantics 5, Bonami, O. \& Cabredo Hofherr, P. (eds.), 255-274.

SigurDsson, Halldór Ármann.

2004 Agree in syntax, agreement in signs. Ms., University of Lund.

SigurDsson, Halldór Ármann.

to appear. The Nominative puzzle and the low Nominative hypothesis. Ms., University of Lund. To appear in Linguistic Inquiry.

Zamparelli, Roberto

2000 Layers in the Determiner Phrase. New York: Garland.

Zamparelli, Roberto

2004 On singular existential quantifiers in Italian. Ms., University of Bergamo. 